\title{
IWIII Health Literacy and the Digital Divide Among Older I Americans
}

\author{
Helen Levy, PhD ${ }^{1,2,3}$, Alexander T. Janke, BS ${ }^{4}$, and Kenneth M. Langa, MD PhD 1,5,6
}

'Survey Research Center, Institute for Social Research, University of Michigan, Ann Arbor, MI, USA; ${ }^{2}$ School of Public Health, University of Michigan, Ann Arbor, MI, USA; ${ }^{3}$ Gerald R. Ford School of Public Policy, University of Michigan, Ann Arbor, MI, USA; ${ }^{4}$ School of Medicine, Wayne State University, Detroit, MI, USA; ${ }^{5}$ Division of General Medicine, Department of Medicine, University of Michigan, Ann Arbor, MI, USA; ${ }^{6}$ Veterans Affairs Center for Clinical Management Research, Ann Arbor, MI, USA.

BACKGROUND: Among the requirements for meaningful use of electronic medical records (EMRs) is that patients must be able to interact online with information from their records. However, many older Americans may be unprepared to do this, particularly those with low levels of health literacy.

OBJECTIVE: The purpose of the study was to quantify the relationship between health literacy and use of the Internet for obtaining health information among Americans aged 65 and older.

DESIGN: We performed retrospective analysis of 2009 and 2010 data from the Health and Retirement Study, a longitudinal survey of a nationally representative sample of older Americans.

PARTICIPANTS: Subjects were community-dwelling adults aged 65 years and older (824 individuals in the general population and 1,584 Internet users).

MAIN MEASURES: Our analysis included measures of regular use of the Internet for any purpose and use of the Internet to obtain health or medical information; health literacy was measured using the Rapid Estimate of Adult Literacy in Medicine-Revised (REALM-R) and self-reported confidence filling out medical forms.

KEY RESULTS: Only $9.7 \%$ of elderly individuals with low health literacy used the Internet to obtain health information, compared with $31.9 \%$ of those with adequate health literacy. This gradient persisted after controlling for sociodemographic characteristics, health status, and general cognitive ability. The gradient arose both because individuals with low health literacy were less likely to use the Internet at all (OR=0.36 [95\% CI 0.24 to 0.54]) and because, among those who did use the Internet, individuals with low health literacy were less likely to use it to get health or medical information (OR=0.60 [95\% CI 0.47 to 0.77]).

CONCLUSION: Low health literacy is associated with significantly less use of the Internet for health information among Americans aged 65 and older. Webbased health interventions targeting older adults must address barriers to substantive use by individuals with low health literacy, or risk exacerbating the digital divide.

Received July 1, 2014

Revised September 8, 2014

Accepted October 4, 2014

Published online November 12, 2014
KEY WORDS: health literacy; electronic health records; aging.

J Gen Intern Med 30(3):284-9

DOI: $10.1007 / \mathrm{s} 11606-014-3069-5$

(C) Society of General Internal Medicine 2014

\section{INTRODUCTION}

Substantial resources and attention have been invested recently in health information technology (IT). ${ }^{1-4}$ The meaningful use incentive program administered by the Centers for Medicare and Medicaid Services (CMS) outlines requirements for electronic medical records (EMRs), among which is the requirement that eligible providers will "provide patients the ability to view online, download, and transmit information" from their medical records. 5

It is unclear, however, whether elderly patients will be able to take advantage of the opportunity afforded by EMRs. While Internet use among older adults is increasing rapidly, as of 2013 , only $59 \%$ of adults aged 65 and older reported that they were online. ${ }^{6}$ Moreover, the proliferation of health IT may exacerbate the digital divide. ${ }^{7-9}$ Vulnerable groups such as African-Americans or those with low socioeconomic status are less likely to use EMRs or patient portals, ${ }^{9-16}$ in part because they are less likely to use the Internet at all. ${ }^{17-20}$

Health literacy may also play an important role in determining whether elderly patients are willing and able to use EMRs and other Internet-based health tools. Surprisingly, given the substantial body of research that documents the importance of health literacy in health behaviors and outcomes, ${ }^{21-23}$ it has been largely overlooked as a determinant of health IT use. ${ }^{24,25}$ One study ${ }^{16}$ used a large sample of patients with diabetes enrolled in a single health plan in northern California to document the importance of health literacy as a predictor of Internet-based patient portal use, even after controlling for basic demographic characteristics. This finding supports the idea that individuals with low health literacy are on the wrong side of the digital divide; however, no population-based study to date has estimated the relationship between health literacy and use of the Internet to obtain health information in the general population of older Americans. The current study fills that gap by exploring both how low health literacy is related to use of the Internet for any purpose and whether, conditional on 
being Internet users, those with low health literacy are less likely to use the Internet for the purpose of obtaining health or medical information.

\section{METHODS}

\section{Setting \& Participants}

We used data from the Health and Retirement Study (HRS), an ongoing nationally representative prospective cohort study of approximately 22,000 individuals aged 51 and older. The HRS is conducted by the University of Michigan under a cooperative agreement with the National Institute on Aging. The design of the HRS is described elsewhere in greater detail. ${ }^{26,27}$ Core surveys are administered in both English and Spanish, with half of the sample receiving an in-person interview and half receiving a telephone interview in each wave. Recent waves of the HRS have achieved response rates above $88 \%,{ }^{26}$ and bias from nonrandom sample attrition is low. ${ }^{28,29}$ The use of survey weights to adjust for the complex sample design and non-response yields estimates that are nationally representative..$^{30,31}$

The current study makes use of data from a special module on health literacy that was administered to a random subset of HRS respondents in 2010 and a supplemental Internet-based survey administered in 2009 to respondents who reported in 2008 that they regularly used the Internet.

In 2010, health literacy questions were slated to be administered to a subsample of 1,168 respondents aged 65 and older randomly drawn from 2010 HRS core respondents who (1) responded to the 2010 core survey themselves, as opposed to having a proxy respondent answer for them, and (2) were included in the random half-sample of respondents receiving face-to-face rather than telephone interviews in 2010. For this analysis, we considered 1,121 community-dwelling respondents 65 years of age or older; of these, 898 completed the health literacy module, for an overall module response rate of $80 \%$. However, 74 of these individuals ultimately completed the module via a telephone interview rather than a face-to-face interview, so they lack results from one of the health literacy measures. Our final sample for analysis, therefore, comprised 824 respondents, for an effective module response rate of $74 \%$. We did find some evidence that in both of the subsamples we used, individuals in worse health or with lower cognitive ability were less likely to provide complete data, an issue we discuss in more detail below.

The 2009 Internet survey was administered to a random subsample of respondents to the 2008 core survey that had reported regular Internet use in that wave. Among those aged 65 and older, 3,406 individuals were contacted for the Internet survey, of whom 2,367 responded, for an overall response rate of $69 \%$. Among those who responded, 1,617 individuals were assigned the health literacy measures from the survey, of whom 1,584 gave valid responses.

\section{Measures}

Internet Use. We characterized Internet use in two ways. First, all participants in the core HRS were asked, "Do you regularly use the World Wide Web - or the Internet - for sending and receiving e-mail or for any other purpose, such as making purchases, searching for information, or making travel reservations?" We considered respondents who answered "yes" to this question as Internet users. Second, participants in the 2009 Internet survey were asked, "How often do you do each of the following activities on the Internet?" Options included "get medical or health information online," among others. Possible responses included: never, rarely, sometimes, or often. We defined those who responded "sometimes" or "often" as individuals who used the Internet for medical or health information.

Health Literacy. Participants in the 2010 health literacy module and the 2009 Internet survey were asked a single health literacy question: "How confident are you filling out medical forms by yourself?" with response options: extremely, quite, somewhat, a little, or not at all. Studies validating this question with more commonly used tests of health literacy, including the Rapid Estimate of Adult Literacy Measure (REALM) and the Short Test of Functional Health Literacy in Adults (S-TOFHLA), have suggested a response of "somewhat confident" or less as a proxy for low health literacy. ${ }^{32-35}$ This measure has been validated in Spanish. $^{36}$ The 2010 health literacy module also included the revised, shortened version of the Rapid Estimate of Adult Literacy in Medicine (REALM-R); we followed established convention defining low health literacy as seven or fewer words pronounced correctly. ${ }^{37,38}$

Cognitive Function. We used three measures of cognitive function included in the HRS: serial sevens subtraction (7 from 100 successively), immediate and delayed recall (from a list of common words), and counting backwards. We defined a composite measure from 0 to 27 , and defined cognitive impairment as a score of 11 or lower, an approach that has been validated using these data. ${ }^{39}$

Health and Function. Self-reported health was assessed with the question, "Would you say your health is excellent, very good, good, fair, or poor?" Impaired function was defined by a self-report of difficulty with activities of daily living (ADLs: dressing, walking, bathing, eating, getting into or out of bed, or using the toilet) and instrumental activities of daily living (IADLs: 
preparing meals, grocery shopping, using the phone, taking medication, or handling money). Previous research using the HRS has established the significance of functional impairment with regard to Internet use. ${ }^{18}$

Demographic and Socioeconomic Characteristics. We also included demographic characteristics (age, race, ethnicity, gender, marital status, and educational attainment) and family income relative to poverty status.

Results were weighted to be nationally representative of community-dwelling Americans aged 65 and older. All standard errors were adjusted to account for the complex sampling design of the HRS. Statistical analyses were performed using Stata version 13 (StataCorp LP, College Station, TX).

\section{RESULTS}

Table 1 summarizes key demographic characteristics in the 2010 health literacy module (general population) sample and the 2009 Internet sample. Internet users were younger, more highly educated, and in better physical and cognitive health than the general population sample. In our general population sample, about $20 \%$ of respondents had low health literacy as measured by the REALM-R, while $40 \%$ had low self-assessed health literacy. In the sample of Internet users (for whom we

Table 1. Characteristics of Study Participants, N (\%)*

\begin{tabular}{|c|c|c|c|c|}
\hline & \multicolumn{2}{|c|}{2010} & \multicolumn{2}{|l|}{2009} \\
\hline & \multicolumn{2}{|c|}{$\begin{array}{l}\text { General } \\
\text { population }\end{array}$} & \multicolumn{2}{|c|}{ Internet users } \\
\hline & \multicolumn{2}{|c|}{$N=824$} & \multicolumn{2}{|c|}{$N=1,584$} \\
\hline $\begin{array}{l}\text { Low health literacy (self- } \\
\text { assessed) }\end{array}$ & 372 & $(42.2 \%)$ & 320 & $(19.3 \%)$ \\
\hline $\begin{array}{l}\text { Low health literacy } \\
\text { (REALM-R) }\end{array}$ & 197 & $(22.1 \%)$ & & \\
\hline Sex female & 469 & $(56.1 \%)$ & 820 & $(49.4 \%)$ \\
\hline \multicolumn{5}{|l|}{ Race } \\
\hline White non-Hispanic & 640 & $(84.3 \%)$ & 1,454 & $(93.5 \%)$ \\
\hline Other non-Hispanic & 124 & $(10.0 \%)$ & 93 & $(4.3 \%)$ \\
\hline Hispanic & 60 & $(5.7 \%)$ & 37 & $(2.2 \%)$ \\
\hline Married or partnered & 491 & $(59.3 \%)$ & 1,184 & $(75.6 \%)$ \\
\hline $\begin{array}{l}\text { Education less than high } \\
\text { school }\end{array}$ & 179 & $(20.1 \%)$ & 89 & $(5.6 \%)$ \\
\hline Poverty & 76 & $(7.6 \%)$ & 29 & $(2.2 \%)$ \\
\hline \multicolumn{5}{|l|}{ Age (years) } \\
\hline $65-69.9$ & 210 & $(33.3 \%)$ & 614 & $(44.6 \%)$ \\
\hline $70.0-74.9$ & 216 & $(22.9 \%)$ & 487 & $(26.7 \%)$ \\
\hline$\geq 75$ & 398 & $(43.8 \%)$ & 483 & $(28.7 \%)$ \\
\hline Internet use & 315 & $(41.0 \%)$ & 1,584 & $(100.0 \%)$ \\
\hline Any chronic health condition & 717 & $(85.5 \%)$ & 1,291 & $(79.2 \%)$ \\
\hline Fair or poor self-rated health & 220 & $(24.0 \%)$ & 226 & $(13.7 \%)$ \\
\hline Functional impairment & 206 & $(24.4 \%)$ & 169 & $(10.4 \%)$ \\
\hline Cognitive impairment & 183 & $(20.4 \%)$ & 129 & $(7.8 \%)$ \\
\hline
\end{tabular}

${ }^{*} N$ not weighted, $\%$ weighted to be nationally representative of community-dwelling Americans aged 65 and older have only the self-assessed measure of health literacy), the fraction with low health literacy was about half of what it was in the general population (Table 1).

Individuals with adequate health literacy were three times more likely than those with low health literacy to use the Internet to obtain health information. Only $9.7 \%$ of older individuals with low health literacy regularly used the Internet for health information, compared with $31.9 \%$ of those with adequate health literacy (Table 2). These differences in healthrelated Internet use were driven both by higher rates of any Internet use among the more literate-only $22.0 \%$ of those with low health literacy regularly used the Internet for any purpose, while $54.8 \%$ of those with adequate literacy did - and a higher likelihood of using the Internet for health information among Internet users with adequate health literacy. These differences suggest the presence of a significant digital divide between individuals with low and high health literacy.

Table 3 presents results of a multivariate analysis relating Internet use to low health literacy, after controlling for other factors likely to influence Internet use. Low health literacy, whether self-assessed or measured using the REALM-R, significantly reduced the odds of regular Internet use (for self-assessed health literacy, $\mathrm{OR}=0.36$ [95 \% CI 0.24 to 0.54 ]; for health literacy measured using REALM-R, OR $=0.25$ [95\% CI 0.15 to $0.41])$. Other covariates were as expected: age greater than 75 years, education less than high school, and low cognitive function were also associated with a lack of regular Internet use. Interestingly, although existing evidence suggests that the relationship between health literacy and other health-related measures in many cases is rendered insignificant by the inclusion of measures of general cognitive function, ${ }^{40,41}$ our results remained robust even after adjusting for these. We also repeated the regression analyses entering scores on each of the three cognitive tests separately (rather than in the combined 27-point scale), and our results were unchanged, so we are reporting the results using the combined 27-point scale.

Table 2. Health Literacy and Internet Use

\begin{tabular}{lllll}
\hline \hline & & \multicolumn{3}{c}{ Health literacy* } \\
\cline { 3 - 5 } & Low & $\begin{array}{c}\text { Not } \\
\text { low }\end{array}$ & P value \\
\hline (1) & $\begin{array}{c}\text { Probability of regular Internet use } \\
\text { (general population; } n=812)\end{array}$ & 0.220 & 0.548 & $P<0.001$ \\
(2) $\quad \begin{array}{c}\text { Probability of obtaining health/ } \\
\text { medical info from Internet } \\
\text { (Internet users only; } n=1,563)\end{array}$ & 0.440 & 0.582 & $P<0.001$ \\
(3) $\quad 0.097$ & 0.319 & $P<0.001$ \\
$\begin{array}{c}\text { Probability of obtaining health/ } \\
\text { medical info from Internet } \\
\text { (general population) [row 1 } \\
\text { times row 2] }\end{array}$ & & & \\
\hline
\end{tabular}

*Health literacy defined as in the self-assessed measure 
Table 3. Multivariate Determinants of Internet Use

\begin{tabular}{|c|c|c|c|c|c|c|}
\hline \multirow{5}{*}{$\begin{array}{l}\text { Low health literacy (self-assessed) } \\
\text { Low health literacy (REALM-R) } \\
\text { Age } \geq 75 \text { years }\end{array}$} & \multicolumn{6}{|c|}{ Adjusted multivariate OR [95 \% CI] } \\
\hline & \multicolumn{4}{|c|}{ Odds of using the Internet at all } & \multicolumn{2}{|c|}{$\begin{array}{l}\text { For Internet users, odds of } \\
\text { obtaining health/medical } \\
\text { info from Internet }\end{array}$} \\
\hline & \multirow[t]{2}{*}{$0.36^{* *}$} & \multirow{2}{*}[0.24\text{to}0.54]{} & & & \multirow[t]{2}{*}{$0.60^{* *}$} & \multirow{2}{*}[0.47\text{to}0.77]{} \\
\hline & & & $0.25^{* *}$ & {$[0.15$ to 0.41$]$} & & \\
\hline & $0.35^{* *}$ & {$[0.25$ to 0.49$]$} & $0.31^{* *}$ & {$[0.22$ to 0.43$]$} & 0.78 & {$[0.60$ to 1.03$]$} \\
\hline \multicolumn{7}{|l|}{ Race } \\
\hline White non-Hispanic & \multicolumn{2}{|l|}{ Reference } & \multicolumn{2}{|c|}{ Reference } & \multicolumn{2}{|c|}{ Reference } \\
\hline Non-white non-Hispanic & $0.44^{*}$ & {$[0.22$ to 0.90$]$} & 0.54 & [0.27 to 1.07$]$ & 1.15 & {$[0.70$ to 1.89$]$} \\
\hline Hispanic & 0.55 & {$[0.07$ to 4.38$]$} & 0.35 & {$[0.06$ to 1.89$]$} & 0.58 & {$[0.23$ to 1.44$]$} \\
\hline Fair or poor self-rated health & $0.42^{* *}$ & {$[0.25$ to 0.71$]$} & $0.43^{* *}$ & {$[0.26$ to 0.72$]$} & 1.28 & {$[0.83$ to 1.97$]$} \\
\hline Chronic condition & 0.86 & {$[0.49$ to 1.51$]$} & 0.88 & {$[0.49$ to 1.57$]$} & 0.94 & {$[0.72$ to 1.25$]$} \\
\hline Functional impairment & 0.69 & {$[0.41$ to 1.16$]$} & $0.60^{*}$ & {$[0.38$ to 0.95$]$} & 0.76 & {$[0.52$ to 1.10$]$} \\
\hline Female sex & 0.88 & {$[0.60$ to 1.28$]$} & 0.78 & {$[0.53$ to 1.16$]$} & 1.20 & {$[0.92$ to 1.56$]$} \\
\hline Married or partnered & $1.87^{* *}$ & {$[1.21$ to 2.90$]$} & $1.89^{* *}$ & [1.28 to 2.79$]$ & 0.99 & {$[0.79$ to 1.24$]$} \\
\hline Education $<$ high school & $0.15^{* *}$ & {$[0.08$ to 0.30$]$} & $0.15^{* *}$ & {$[0.08$ to 0.30$]$} & 0.79 & {$[0.51$ to 1.23$]$} \\
\hline Poverty & 0.58 & {$[0.22$ to 1.53$]$} & 0.57 & {$[0.21$ to 1.56$]$} & $2.24^{*}$ & {$[1.00$ to 4.99$]$} \\
\hline Cognitive impairment & $0.43^{*}$ & {$[0.22$ to 0.84$]$} & $0.43^{* *}$ & {$[0.24$ to 0.76$]$} & 0.76 & {$[0.49$ to 1.16$]$} \\
\hline Sample includes: & \multicolumn{2}{|c|}{ General population } & \multicolumn{2}{|c|}{ General population } & \multicolumn{2}{|c|}{ Internet users only } \\
\hline$N$ & \multicolumn{2}{|c|}{824} & \multicolumn{2}{|c|}{824} & \multicolumn{2}{|c|}{1,584} \\
\hline
\end{tabular}

Among regular Internet users, $55.4 \%$ (95 \% CI 52.1 to $58.9 \%$ ) reported using the Internet sometimes or often to get medical or health information online. Low health literacy significantly reduced the odds of Internet use for medical or health information $(\mathrm{OR}=0.60[95 \%$ CI 0.47 to 0.77$]$ ). Low cognition had relatively less impact on the likelihood of using the Internet for medical or health information, conditional on use of the Internet. That is, our results suggest that once older adults do use the Internet for any task, poor cognition is a smaller barrier than low health literacy with respect to Internet for health-related tasks.

\section{DISCUSSION}

In a nationally representative sample of older U.S. adults, we found that health literacy was a significant predictor of Internet use. For those who did use the Internet, low health literacy was also predictive of what they did once they were online; individuals with low health literacy were significantly less likely to use the Internet for medical or health information. These patterns persisted even after adjusting for demographic covariates including age, sex, and race, as well as clinical covariates such as chronic medical conditions, functional impairment, and cognition. Interestingly, though past evidence has suggested that health literacy may be a proxy for general cognition, ${ }^{40,41}$ our results suggest that each has an independent relationship with likelihood of regular Internet use. We found that health literacy was a more important predictor of Internet use for medical or health information than was level of cognitive function, suggesting that interventions specifically targeting health literacy among Internet-using older adults may be effective for narrowing the digital divide by facilitating their ability to obtain medical information online.

This study was the first to examine the importance of health literacy as a predictor of Internet use for obtaining health information, a topic that, surprisingly, has been overlooked in nearly all prior studies of Internet use. In contrast to an earlier study documenting the importance of self-assessed health literacy as a predictor of patient portal use in a sample of diabetes patients enrolled in a single health plan in northern California, we used data that were nationally representative of older Americans. We also measured health literacy using the REALM-R in addition to self-assessed health literacy.

Our study did have a number of potential limitations. Our analysis was limited to individuals 65 and older. Older cohorts of adults have been slower than younger cohorts to adopt Internet technology related to health ${ }^{42}$; the effect of health literacy on the use of these technologies could be either smaller or larger among younger cohorts. As mentioned above, individuals in worse physical or cognitive health appeared less likely to provide complete data for the survey components that we used, raising concerns about selection bias. We believe, however, that any bias is unlikely to affect the differential in Internet use between individuals with low and high health literacy.

Another limitation was that other important patient attributes such as patient activation ${ }^{43,44}$ or selfefficacy $^{45}$ were not available in our data; omitting these variables from the analysis may have overstated the true relationship between health literacy and Internet use-if 
they are, indeed, positively correlated with both health literacy and use of the Internet. In this case, our estimates overstated the true independent effect of low health literacy on Internet use, and future work with a more extensive set of covariates will be needed to address this problem.

A final concern is that the outcome measures that we used - use of the Internet for any reason and, conditional on using the Internet at all, using it to get health or medical information-are more general than, for example, whether individuals in a particular health plan use that plan's patient portal. This generality is both a strength and weakness. It allows us to understand the extent to which older individuals with low health literacy are not even at the starting gate in utilizing specialized applications such as a patient portal, in that they do not use the Internet at all. We found that this fundamental obstacle was highly prevalent: more than threequarters of older individuals with low health literacy did not use the Internet for any purpose. At the same time, our measure of health-related Internet use-obtaining any health or medical information on the Internet-likely overstated the extent to which some of these individuals would, in fact, be able to navigate a patient portal or other more specialized Web-based health interventions. The small fraction of older individuals with low health literacy who used the Internet to obtain health or medical information-9.7\%-is almost certainly higher than the fraction that would be able to adopt sophisticated health information technologies to effectively interact with their EMRs. Further research on such interventions using population-based samples should be a high priority, with a focus on identifying features of interventions that make them accessible to older individuals with low health literacy.

\section{CONCLUSION}

Individuals with low health literacy represent a vulnerable population who are at high risk of being left behind by the advance of technology. Our results suggest that a simple measure of health literacy - confidence filling out medical forms - is effective at identifying individuals who are less likely to use the Internet to obtain information about health. Interventions to improve health literacy may have a spillover benefit of lowering barriers to effective use of information technology. Even in the absence of such interventions, screening for low health literacy in the clinical setting can help clinicians identify patients who are likely to have difficulty adopting electronic health technology.

Health information technology, like any innovation in health care, ${ }^{46}$ offers both the promise of significant benefits and the risk that these benefits will not be shared equally. Low health literacy may attenuate the effectiveness of Web-based interventions to improve the health of vulnerable populations. As Internet use becomes increasingly relevant to the provision of health care ${ }^{42}$ programs must address barriers to substantive use among vulnerable populations, or otherwise risk deepening the existing disparities in access and outcomes.

ACKNOWLEDGMENTS: The Health and Retirement Study is sponsored by the National Institute on Aging (grant number NIA U01AG009740) and is conducted by the University of Michigan. $H$. Levy acknowledges financial support from the National Institute on Aging (grant numbers NIA K01AG034232 and NIA P01AG026571). A. Langa acknowledges financial support from the National Academies Keck Futures Initiative (grant number NAKFI IB5).

There were no presentations of this work prior to acceptance of this manuscript.

Conflict of Interest: The authors each declare that they not have no conflict of interest.

Corresponding Author: Helen Levy, PhD; Survey Research Center, Institute for Social ResearchUniversity of Michigan, 426 Thompson St., Ann Arbor, MI 48104, USA (e-mail: hlevy@umich.edu).

\section{REFERENCES}

1. Kumar S, Nilsen WJ, Abernethy A, et al. Mobile health technology evaluation: the mHealth evidence workshop. Am J Prev Med. 2013;45(2):228-236.

2. Marcotte L, Seidman J, Trudel $\mathbf{K}$, et al. Achieving meaningful use of health information technology: a guide for physicians to the EHR incentive programs. Arch Intern Med. 2012;172(9):731-736.

3. Sarkar U, Bates DW. Care partners and online patient portals. JAMA. 2014;311(4):357-358.

4. Steinhubl SR, Muse ED, Topol EJ. Can mobile health technologies transform health care? JAMA. 2013;310(22):2395-2396.

5. Stage 1 Meaningful Use (2014 definition) Eligible Professional Meaningful Use Table of Contents. EHR Incentive Program 2014.

6. Smith A. Older Adults and Technology Use. Washington: Pew Research Center; 2014.

7. Parker RM, Ratzan SC, Lurie N. Health literacy: a policy challenge for advancing high-quality health care. Health Aff. 2003;22(4):147153.

8. Viswanath K, Kreuter MW. Health disparities, communication inequalities, and eHealth. Am J Prev Med. 2007;32(5 Suppl):S131S133.

9. Yamin CK, Emani S, Williams DH, et al. The digital divide in adoption and use of a personal health record. Arch Intern Med. 2011;171(6):568574

10. Ancker JS, Barrón Y, Rockoff ML, et al. Use of an electronic patient portal among disadvantaged populations. J Gen Intern Med. 2011;26(10):1117-1123.

11. Goel MS, Brown TL, Williams A, Hasnain-Wynia R, Thompson JA, Baker DW. Disparities in enrollment and use of an electronic patient portal. J Gen Intern Med. 2011;26(10):1112-1116.

12. Goldzweig CL, Orshansky G, Paige NM, et al. Electronic patient portals: evidence on health outcomes, satisfaction, efficiency, and attitudes a systematic review. Ann Intern Med. 2013;159(10):677-687.

13. Kim E-H, Stolyar A, Lober WB, et al. Challenges to using an electronic personal health record by a low-income elderly population. J Med Internet Res. 2009;11(4):e44.

14. Lober WB, Zierler B, Herbaugh A, et al. Barriers to the use of a personal health record by an elderly population. Paper presented at: AMIA Annual Symposium Proceedings; 2006. 
15. Roblin DW, Houston TK II, Allison JJ, Joski PJ, Becker ER. Disparities in use of a personal health record in a managed care organization. J Am Med Inform Assoc. 2009;16(5):683-689.

16. Sarkar U, Karter AJ, Liu JY, et al. The literacy divide: health literacy and the use of an Internet-based patient portal in an integrated health system-results from the Diabetes Study of Northern California (DISTAN CE). J Health Commun. 2010;15(sup2):183-196.

17. Chang BL, Bakken S, Brown SS, et al. Bridging the digital divide: reaching vulnerable populations. J Am Med Inform Assoc. 2004;11(6):448-457.

18. Greysen S, Chin Garcia C, Sudore RL, Cenzer I, Covinsky KE. Functional impairment and Internet use among older adults: Implications for meaningful use of patient portals. JAMA Intern Med 2014; 174(7): 1188-1190.

19. Elliot AJ, Mooney CJ, Douthit KZ, Lynch MF. Predictors of older adults' technology use and its relationship to depressive symptoms and well-being. J Gerontol Ser B Psychol Sci Soc Sci. 2013;69(5):667-677.

20. Gell NM, Rosenberg DE, Demiris G, LaCroix AZ, Patel KV. Patterns of technology use among older adults with and without disabilities. The Gerontologist. 2013. doi:10.1093/geront/gnt166.

21. Baker DW, Wolf MS, Feinglass J, Thompson JA, Gazmararian JA, Huang $\mathbf{J}$. Health literacy and mortality among elderly persons. Arch Intern Med. 2007;167(14):1503-1509.

22. Berkman ND, Sheridan SL, Donahue KE, Halpern DJ, Crotty K. Low health literacy and health outcomes: an updated systematic review. Ann Intern Med. 2011;155(2):97-107.

23. Sudore RL, Yaffe $\mathbf{K}$, Satterfield S, et al. Limited literacy and mortality in the elderly: the health, aging, and body composition study. J Gen Intern Med. 2006;21(8):806-812.

24. Kaelber DC, Jha AK, Johnston D, Middleton B, Bates DW. A research agenda for personal health records (PHRs). J Am Med Inform Assoc. 2008; 15(6):729-736

25. Weinstein RS, Lopez AM. Health literacy and connected health. Health Aff. 2014;33(6): 1103-1104.

26. Sonnega A, Faul JD, Ofstedal MB, Langa KM, Phillips JW, Weir DR. Cohort profile: the Health and Retirement Study (HRS). Int J Epidemiol. 2014;43(2):576-585.

27. Juster FT, Suzman R. An overview of the health and retirement study. J Hum Resour. 1995;30:S7-S56.

28. Cheshire H, Ofstedal MB, Scholes S, Schröder M. A comparison of response rates in the English longitudinal study of ageing and the health and retirement study. Longitud Life Course Stud. 2011;2(2):127.

29. Weir DR, Faul JD, Langa KM. Proxy interviews and bias in cognition measures due to non-response in longitudinal studies: a comparison of HRS and ELSA. Longitud Life Course Stud. 2011;2(2):170-184.
30. Heeringa SG, Connor JH. Technical description of the Health and Retirement Survey sample design. Ann Arbor: University of Michigan; 1995

31. Ofstedal M, Weir D, Chen $\mathbf{K}$, Wagner J. Updates to HRS sample weights. Ann Arbor: University of Michigan; 2011.

32. Chew LD, Griffin JM, Partin M, et al. Validation of screening questions for limited health literacy in a large VA outpatient population. J Gen Intern Med. 2008;23(5):561-566.

33. Chew LD, Bradley KA, Boyko EJ. Brief questions to identify patients with inadequate health literacy. Fam Med. 2004;36(8):588-594

34. Powers BJ, Trinh JV, Bosworth HB. Can this patient read and understand written health information? JAMA. 2010;304(1):76-84.

35. Wallace LS, Rogers ES, Roskos SE, Holiday DB, Weiss BD. BRIEF REPORT: screening items to identify patients with limited health literacy skills. J Gen Intern Med. 2006;21(8):874-877.

36. Sarkar U, Schillinger D, López A, Sudore R. Validation of self-reported health literacy questions among diverse English and Spanish-speaking populations. J Gen Intern Med. 2011;26(3):265-271.

37. Bass PF, Wilson JF, Griffith CH. A shortened instrument for literacy screening. J Gen Intern Med. 2003;18(12):1036-1038.

38. Davis TC, Long SW, Jackson RH. Rapid estimate of adult literacy in medicine: a shortened screening instrument. Fam Med. 1993;25:391-395.

39. Crimmins EM, Kim JK, Langa KM, Weir DR. Assessment of cognition using surveys and neuropsychological assessment: the health and retirement study and the aging, demographics, and memory study. J Gerontol Ser B Psychol Sci Soc Sci. 2011;66(suppl 1):i162-i171.

40. Serper M, Patzer RE, Curtis LM, et al. Health literacy, cognitive ability, and functional health status among older adults. Health Serv Res. 2014:n/ $\mathrm{a}-\mathrm{n} / \mathrm{a}$.

41. Wolf MS, Curtis LM, Wilson EA, et al. Literacy, cognitive function, and health: results of the LitCog study. J Gen Intern Med. 2012;27(10):1300 1307.

42. Fox S, Jones S. The social life of health information. Pew Internet \& American Life Project: Washington, DC; 2009:2009-2012.

43. Greene J, Hibbard JH, Tusler M. How much do health literacy and patient activation contribute to older adults' ability to manage their health? : AARP Public Policy Institute Washington, DC; 2005.

44. Smith SG, Curtis LM, Wardle J, von Wagner C, Wolf MS. Skill set or mind set? Associations between health literacy, patient activation and health. PLOS ONE. 2013;8(9):e74373.

45. Wolf MS, Davis TC, Osborn CY, Skripkauskas S, Bennett CL, Makoul G. Literacy, self-efficacy, and HIV medication adherence. Patient Educ Couns. 2007;65(2):253-260.

46. Glied S, Lleras-Muney A. Technological innovation and inequality in health. Demography. 2008;45(3):741-761. 